\title{
A Pilot Study to Investigate the Use of the ICF IN DOCUMENTING LEVELS OF FunCTION AND Disability in People Living with HIV
}

\begin{abstract}
Objective: The study was a pilot study aimed at investigating the use of the International Classification of Functioning, Disability and Health (ICF) checklist developed by the World Health Organisation in determining the function of individuals living with HIV in a township near Cape Town.

Methods: Twelve participants attending the HIV clinic were examined using the ICF checklist.

Findings: Areas of the ICF in which problems were noted included emotional functioning and energy and drive. Four participants complained of increased sensitivity to sound. Several respondents (three) reported difficulties in relationships with community members, with less having problems in family and intimate relationships. Conclusion: The ICF was found to be time consuming and many codes were not relevant. Some of the concepts were not well understood by the participants. However, despite limitations, the use of the ICF in a resource poor setting formed a useful framework within which to examine the functional problems of HIV infected individuals. In the absence of any equivalent unifying framework within which to classify health and health related states, the use of the ICF merits further investigation.
\end{abstract}

KEY WORDS: ICF, HIV, STIGMA.

\section{INTRODUCTION}

The World Health Organisation (WHO) has recognised the need to set guidelines on the development and reform of health care systems (Sibai, 2004)( Sibai 2004) and to this end has developed the Family of International Classifications of medical conditions and their consequences. The flagship of these classifications was the International Statistical Classification of Diseases and Related Health Problems (ICD), now in the 10th Revision (World Health Organisation, 1992) In 1980, the ICD was complemented by the development of the International Classification of Impairments, Disabilities and Handicaps (World Health Organisation, 1980). This classification was amended after a long process of consultation and testing (World Health Organization, 2001). The revised version, The International Classification of Functioning, Disability and Health (ICF) was ratified by the WHO Assembly in May 2001. The stated aims of the ICF are (World Health Organization, 2001):

- To provide a scientific basis for understanding and studying health and health related states.

- To establish a common language amongst health care workers, and other stake holders

- To permit comparison of data across different contexts

- To provide a systematic coding scheme for health information systems.

The conceptual framework, which emphasizes the inter-related nature of the functional impairments, the activity and participation limitations and environmental factors, has been welcomed as a way to better understand and document the disability process in both children (Rosenbaum et al., 2004) and adults (Bilbao et al., 2003). The classification is complex and attempts to encompass all areas of human functioning. (See Table 1). There are three major classification sections, that of impairment (consisting of b-codes, impairment of body structure and s-codes, impairment of structure), activity and participation (d-codes) and environmental factors (e-codes). The ICF can be used at different levels depending on the amount of detail required or available. In addition to the basic descriptive coding there are also qualifiers which elaborate on the degree of functioning or impairment of functioning in each domain and the degree to which contextual factors help or hinder functioning (World Health Organization, 2001). The ICF checklist, (World Health Organisation, 2003) which is available on the Web, consists of 126 items, grouped under the different codes mentioned above.

The ICF is potentially a very important instrument with which to improve the documentation of functioning. However, due to the relative infancy of the instrument, little literature is available on its performance, validity and reliability within different clinical and community settings. Bornman examined the ICF in a South African setting and concluded that it was a useful instrument

\section{CORRESPONDENCE TO:}

\section{J Jelsma}

Division of Physiotherapy,

School of Health and

Rehabilitation Sciences,

Faculty of Health Sciences

University of Cape Town,

Anzio Road, Observatory 7925

Fax: (27-21) 448-8157

Tel: (27-21) 406-6402

E-mail: jjelsma@uctgsh1.uct.ac.za 
for the monitoring of disability in people with severe disability (Bornman, 2004). To the knowledge of the researchers the instrument has not been tested in a community setting with poor resources.

The HIV/AIDS pandemic has reached catastrophic proportions in Sub-Saharan Africa. In 2004, it was estimated that just over 5 million people out of the population of 46 million were living with HIV, resulting in a total population prevalence rate of $11 \%$ (Dorrington et al., 2004). The virus has many and complex effects on the body and can be expected to have a marked impact on the functioning of individuals in everyday life (Heaton et al., 2004). The health related quality of life (HRQoL) of people living with HIV/AIDS in South Africa (Hughes et al., 2004) and elsewhere (Murri et al., 2003) has been documented and found to be severely compromised in terms of mobility, pain, anxiety and depression and in the ability to maintain usual activities. In addition people living with HIV/AIDS rate their own health state as being significantly lower than reference groups.

The site of the current study was a HIV clinic in a Xhosa-speaking, resource poor, high-density community situated close to Cape Town. At the time the study was undertaken, no antiretroviral therapy was dispensed although treatment roll-out was anticipated in the near future. No previous research could be found using the ICF to examine the level of functioning of adults living with HIV in South Africa.

Table 1: An overview of the ICF.

\begin{tabular}{|l|l|l|}
\hline SECTION & Component & Domains \\
\hline Functioning and Disability & Body & $\begin{array}{l}\text { Functions of body systems } \\
\text { Body structures }\end{array}$ \\
\hline Contextual Factors & Activities and Participation & Life areas (tasks, actions) \\
\hline & Environmental Factors & External influences on functioning and disability \\
\hline
\end{tabular}

(World Health O rganization, 2001)

Table 2: Impairments of function.

\begin{tabular}{|c|c|c|c|c|c|c|}
\hline Domain & Code & No & Mild & Moderate & Severe & Complete \\
\hline \multirow[t]{3}{*}{ Mental Functions (B1) } & $\begin{array}{l}\text { B130-Energy } \\
\text { and drive functions }\end{array}$ & 6 & 1 & 3 & 0 & 2 \\
\hline & B144-M emory & 7 & 4 & 1 & 0 & 0 \\
\hline & $\begin{array}{l}\text { B152-Emotional } \\
\text { functions }\end{array}$ & 6 & 0 & 3 & 2 & 1 \\
\hline $\begin{array}{l}\text { Sensory Functions and Pain } \\
\text { (B2) }\end{array}$ & B280-Pain & 4 & 1 & 3 & 4 & 0 \\
\hline $\begin{array}{l}\text { Functions of Cardiovascular } \\
\text { and Respiratory Systems (B4) }\end{array}$ & $\begin{array}{l}\text { B440-Respiration } \\
\text { (Breathing) }\end{array}$ & 5 & 3 & 3 & 1 & 0 \\
\hline \multirow{3}{*}{$\begin{array}{l}\text { Functions of the Digestive } \\
\text { System (B5) }\end{array}$} & B515-Digestive & 8 & 0 & 3 & 1 & 0 \\
\hline & B525- Defecation & 8 & 0 & 3 & 1 & 0 \\
\hline & $\begin{array}{l}\text { B530-W eight } \\
\text { Maintenance }\end{array}$ & 5 & 3 & 3 & 0 & 1 \\
\hline Reproductive Functions (B6) & $\begin{array}{l}\text { B640-Sexual } \\
\text { Functions }\end{array}$ & 11 & 0 & 0 & 0 & 0 \\
\hline \multirow{2}{*}{$\begin{array}{l}\text { N euromusculoskeletal and } \\
\text { Movement related Functions } \\
\text { (B7) }\end{array}$} & $\begin{array}{l}\text { B710-M obility of } \\
\text { Joint }\end{array}$ & 7 & 2 & 0 & 3 & 0 \\
\hline & B730-M uscle Power & 8 & 1 & 3 & 0 & 0 \\
\hline Functions of the Skin (B8) & B8-Skin Conditions & 7 & 2 & 2 & 0 & 1 \\
\hline
\end{tabular}


The purpose of this project was to critically examine the performance of the ICF in a resource poor population by investigating whether the ICF was able to adequately capture the levels of functioning and disability of adults living with HIV. As the ICF checklist alone has more than 125 categories, reliability testing, which would require at least 10 responses per item, was not done. It was also felt that it would be premature to embark on such a study before the utility of the instrument was examined within a local context.

\section{METHODS}

A cross sectional study design was used. Quantitative data was supplemented by open questioning during interview.

\section{Subjects}

A small self-selected sample of convenience of people living with HIV and attending the HIV Clinic was utilised. HIV was chosen because the impact of the disease is wide-ranging and diverse and it was anticipated that a number of codes would be required to describe the functioning of affected individuals. The sample was limited by several factors, including the time consuming nature of the interview, which discouraged participants from taking part in the study. The lack of a standardised translation of the ICF required that all subjects be able to speak English. The third limiting factor was that each subject should agree to be interviewed by researchers who were not a part of the clinical team managing their conditions. All subjects who met these criteria were included in the study. Instrumentation

The ICF-checklist is an abbreviated list of ICF codes which measures health related functional states of individuals through a coding system that is specified through the use of qualifiers. The five researchers attended a two day training workshop on the use of the ICF led by a technical advisor to the WHO. The English version of the ICF checklist was utilised. The section on impairments of body structures was not included, as this is primarily an anatomical classification. Procedure

Piloting of the procedure was undertaken and the initial interviews were conducted in the presence of all the interviewers in order to standardize the man- ner in which questions were asked. Interviews were conducted in a private venue within the clinic. Interviews lasted between 45 - 60 minutes depending on the amount of information disclosed by the participant.

\section{Data Analysis}

The results of the interviews were analysed using descriptive statistics.

\section{Ethical Considerations}

The University of Cape Town Medical Research Ethics Committee approved the study and in order to maintain confidentiality, informed consent was obtained from each individual by the Clinic Staff before the person was referred to the research team. Participants were compensated with approximately R25.00 for their time and travel costs.

\section{RESULTS}

Twelve subjects were interviewed in this study. The sample consisted of ten females and two males between the ages of twenty and forty-nine years (mean 30.58 , SD 10.8). Six of the subjects were looking for work, five were in formal employment and one was retired. Health conditions, apart from HIV, that were reported included Tuberculosis, Herpes simplex, oesophageal thrush and painful skin rashes.

The areas in which impairments were noted are depicted in Table 2. Domains in which no problems were reported are not included. The numbers in brackets refer to the ICF codes for these problems. In the Mental Functioning domain (b1) of the ICF, the main areas where changes had occurred were energy and drive functioning; memory and emotional functions. Participants had trouble with getting up in the morning and starting the day, as they felt drained and depressed. A fair number (six) reported needing an "afternoon sleep". They also had problems in remembering small details that they felt they used to be able to remember. The most noticeable change in the Sensory functions and Pain domain (b2) was that of pain. The majority of people reported experiencing some degree of pain. Examples were painful skin rashes, joint pains, muscular pains and chest pains. No problems were reported in the (b3), Voice and speech functions. Respiration and breathing was the most relevant in the domain of
Functions of the Cardiovascular and Respiratory Systems (b4). More than half the participants had changes in this area, many with chest pains, shortness of breath and coughs. Functions of the Digestive and Metabolic Systems (b5) domain showed the most changes in digestive function, defecation function and weight maintenance. Participants felt that they had unexplained weight loss or were unable to maintain a certain weight. Some reported diarrhoea and others a loss of appetite.

Sexual function in the Reproductive Functioning (b6) domain showed only one participant to have a problem in this area. In the Neuromusculoskeletal and Movement Related Functions (b7) domain almost half the subjects reported changes in joint mobility and muscle power. Main complaints were of aching and stiffness of the joints, as well as general body weakness and decline of muscle power. Nearly half the subjects reported negative changes in their skin condition under Functions of the skin (b8), painful skin rashes being the most common complaint.

The $d$ codes refer to the activity and participation codes and the results of this section are listed in Table 3. In this section of the ICF checklist, there are two categories namely Performance and Capacity. Only the performance category (the participant's ability to perform a task in their environment) is reported as there were minimal differences between the scores of the two categories.

There were no problems identified in the domains of Learning and Applying Knowledge (d1) or Communication (d3), although memory had been identified as an impairment of function. Responses to General Tasks and Demands (d2) demonstrated that three participants had problems with completing tasks, both single and multiple. When there was a complaint it was generally due to lack of concentration. In the Mobility Area (d4) most of the subjects reported not having any problems and only two subjects had problems in Lifting and carrying heavy objects, as can be seen in Table 2.

Responses to the Self-Care (d5) and Domestic Life (d6) domains indicated that two subjects were experiencing problems in the categories of Doing Housework and Toileting while the 
majority reported to be coping with their own self-care and domestic life. In the domain of Interpersonal Interactions and Relationships (d7), some difficul- ties were found in family relationships and intimate relationships. More of the subjects $(n=4)$ reported problems with interactions with their family and inti- mate relations than they did with strangers. Concerning the Major Life Areas (d8), one important finding under remunerative employment was that half

Table 3: Activity and Participation Limitations $(n=12)$. Only domains with problems are listed. The frequencies of responses to the severity of limitations are presented.

\begin{tabular}{|c|c|c|c|c|c|c|}
\hline & Code & No & Mild & Moderate & Severe & Complete \\
\hline \multirow[t]{6}{*}{ Mobility (d4) } & $\begin{array}{l}\text { d430-Lifting and } \\
\text { Carrying } 0 \text { bjects }\end{array}$ & 10 & 1 & 1 & - & - \\
\hline & d440-Fine Hand Use & 12 & - & - & - & - \\
\hline & d450-W alking & 11 & - & 1 & - & - \\
\hline & $\begin{array}{l}\mathrm{d} 465 \text {-M oving around } \\
\text { using Equipment }\end{array}$ & 1 & - & - & - & - \\
\hline & $\begin{array}{l}\mathrm{d} 470 \text {-Using } \\
\text { transportation }\end{array}$ & 11 & 1 & - & - & - \\
\hline & d475-Driving & 4 & - & - & - & - \\
\hline \multirow[t]{7}{*}{ Self Care (d5) } & $\begin{array}{l}\text { d510-W ashing } \\
\text { O neself }\end{array}$ & 12 & - & - & - & - \\
\hline & $\begin{array}{l}\text { d520-Caring for } \\
\text { Body Parts }\end{array}$ & 12 & - & - & - & - \\
\hline & d530-Toileting & 10 & 1 & - & 1 & - \\
\hline & d540-Dressing & 12 & - & - & - & - \\
\hline & d550-Eating & 12 & - & - & - & - \\
\hline & d560-Drinking & 11 & 1 & - & - & - \\
\hline & $\begin{array}{l}\text { d570-Looking A fter } \\
\text { O ne's Health }\end{array}$ & 12 & - & - & - & - \\
\hline \multirow[t]{4}{*}{ Domestic Life (d6) } & $\begin{array}{l}\text { d620-A cquisition of } \\
\text { goods and services }\end{array}$ & 11 & - & 1 & - & - \\
\hline & $\begin{array}{l}\text { d630-Preparation of } \\
\text { Meals }\end{array}$ & 11 & 1 & - & - & - \\
\hline & $\begin{array}{l}\text { d640-doing } \\
\text { Housework }\end{array}$ & 10 & 1 & - & 1 & - \\
\hline & $\begin{array}{l}\text { d } 660 \text {-A ssisting } \\
0 \text { thers }\end{array}$ & 11 & 1 & - & - & - \\
\hline \multirow[t]{3}{*}{$\begin{array}{l}\text { Interpersonal Interactions / } \\
\text { Relationships (d7) }\end{array}$} & $\begin{array}{l}\text { d720-Complex } \\
\text { Interpersonal } \\
\text { Interactions }\end{array}$ & 9 & 1 & 1 & 1 & - \\
\hline & $\begin{array}{l}\text { d760-Family } \\
\text { Relationships }\end{array}$ & 8 & - & 2 & 2 & - \\
\hline & $\begin{array}{l}\text { d770-Intimate } \\
\text { Relationships }\end{array}$ & 8 & 1 & - & 2 & - \\
\hline Major Life Areas (d8) & $\begin{array}{l}\text { d850-Remunerative } \\
\text { Employment }\end{array}$ & 8 & - & 1 & 3 & - \\
\hline
\end{tabular}


of the subjects were unemployed and thus reported a problem in this area. No subjects reported problems in the domain of Community, Social and Civic Life (d9).

Under the Second Section, Environmental Factors, subjects can code whether the factor is either a barrier that makes one's life more difficult or a facilitator which makes one's life easier. Table 4 depicts the responses to the natural environment and the impact of support and relationships. Four subjects complained of a new sensitivity to sound. This code falls into the domain of Natural Environment, and Human Made Change to Environment (e2). The area of Support and Relationships (e3) revealed that generally health care professionals, personal care providers and people in positions of authority were facilitators, as were members of their immediate family. The areas where negative changes occurred were with friends and with acquaintances, peers, colleagues, neighbours and community members. The participants who reported a barrier generally felt that neither their friends nor their community were very accepting of people living with HIV.

Most people reported the Attitudes (e4) (Table 4) of different groups of people to be a facilitator. Yet, some reported a negative feeling about the attitudes of their friends and the community toward HIV. This was seen in societal attitudes and social norms, practices and ideologies.

\section{DISCUSSION}

\section{Sample}

The small sample cannot be considered representative of the community of

Table 4: Environmental factors $(n=12)$. Only domains $w$ ith problems are listed.

\begin{tabular}{|c|c|c|c|c|c|c|c|c|c|c|}
\hline & Code & 4 & 3 & 2 & 1 & $\mathbf{0}$ & -1 & -2 & -3 & -4 \\
\hline $\begin{array}{l}\text { Natural Environment } \\
\text { and Human Made } \\
\text { Changes } \\
\text { to Environment(e2) }\end{array}$ & e250-Sound & - & - & - & - & 8 & 1 & 2 & - & 1 \\
\hline Support and & e310-Immediate family & 9 & 2 & 1 & - & - & - & - & - & - \\
\hline \multirow[t]{6}{*}{ Relationships(e3) } & e320-Friends & 4 & 2 & 1 & - & 3 & - & 2 & - & - \\
\hline & $\begin{array}{l}\text { e325-A quaintances, peers, } \\
\text { colleagues, neighbours } \\
\text { and community members }\end{array}$ & 3 & 1 & 1 & - & 4 & - & 1 & 1 & 1 \\
\hline & $\begin{array}{l}\text { e330-People in } \\
\text { position of Authority }\end{array}$ & 8 & 2 & 1 & - & 1 & - & & - & - \\
\hline & $\begin{array}{l}\text { e340-Personal Care } \\
\text { providers and } \\
\text { personal assistants }\end{array}$ & 7 & 1 & 1 & - & 3 & - & - & - & - \\
\hline & $\begin{array}{l}355 \text {-Health } \\
\text { professionals }\end{array}$ & 8 & 3 & 1 & - & - & - & - & - & - \\
\hline & $\begin{array}{l}\text { e360-Health related } \\
\text { professionals }\end{array}$ & 7 & 3 & 2 & - & - & - & - & - & - \\
\hline \multirow[t]{6}{*}{ A ttitudes(e4) } & $\begin{array}{l}\text { e410-Individual attitudes of } \\
\text { immediate family members }\end{array}$ & 11 & - & - & - & 1 & - & - & - & - \\
\hline & $\begin{array}{l}\text { e420-Individual attitudes } \\
\text { of friends }\end{array}$ & 4 & 1 & 2 & - & 2 & - & 2 & - & 1 \\
\hline & $\begin{array}{l}\text { e } 440 \text {-Individual attitudes } \\
\text { of personal care providers } \\
\text { and personal assistants }\end{array}$ & 8 & 2 & - & - & 2 & - & - & - & - \\
\hline & $\begin{array}{l}\text { e } 450 \text {-Individual attitudes } \\
\text { of health professionals }\end{array}$ & 10 & 1 & - & - & 1 & - & - & - & - \\
\hline & $\begin{array}{l}\text { e445-Individual attitudes of } \\
\text { health related professionals }\end{array}$ & 10 & 1 & - & - & 1 & - & - & - & - \\
\hline & e460-Societal attitudes & 1 & 1 & 5 & - & 1 & - & - & 2 & 2 \\
\hline
\end{tabular}

Key: 4 Complete Facilitator, 3 Substantial Facilitator, 2 Moderate Facilitator, 1 M ild Facilitator, 0 N o Barrier/ Facilitator,

-1 M ild Barrier, -2 Moderate Barrier, -3 Severe Barrier, -4 Complete Barrier 
people living with HIV due to gender imbalance, language requirements and the requirement of willingness to disclose their HIV status to the researchers. (most people in Masi are female!). The sample was restricted to those attending the HIV clinic on an outpatient basis, i.e. people well enough to be living at home and who were healthy enough to get to the clinic. However, the intention of the study was to examine the performance of the ICF rather than to document the functional problems typical of people living with HIV and this sample provided the researchers with valuable information related to the use of the ICF and the experiences of the people living with HIV.

\section{Findings}

The functional limitations reported were generally consistent with the literature. Conversely, in several domains results were different to the initial expectations and areas of limitation would not have been identified without the use of a comprehensive checklist. Several studies have identified problems in the areas of mood and depression(Heaton et al., 2004), (Hughes et al., 2004). Unsurprisingly half the subjects reported changes in the related areas of emotional functioning and energy and drive.

Unexpectedly a number of people complained of increased sensitivity to sound. This often prevented some subjects from falling asleep easily and one subject reported that he was unable to concentrate if there was background music. As this finding was not expected, it would not have been picked up if the ICF checklist had not been utilised.

The Environmental Factors Part was invaluable in identifying the major positive and negative external factors impacting on functioning. All of the subjects reported persons in positions of authority and the Health and Health related professionals to be facilitatory in the Support and Relationship (e3) and Attitudes (e4) domains. It would appear that the HIV Clinic is playing an extremely important role in the support of those suffering from HIV.

The main problem for HIV participants was found to be fear of disclosure due to expected stigmatisation from the community, as reported by other authors
(Alubo, 2002; Alubo et al., 2002)(Medley et al., 2004). The ICF, with its domains of Support and Relationships (e3) as well as Attitudes (e4), provided a good starting point from which to explore perceptions and effects of stigma on the individual.

\section{Performance of the ICF}

The ICF provided a basis for discussion around functional problems and offered a useful framework within which to explore the functional problems associated with HIV and related illnesses. However, data gathering, coding and entry were extremely time consuming and unlikely to happen within routine practice. Not all of the domains were of relevance and asking questions related to these domains further increased the time for interview. As most of the interviewees were minimally educated and second language English speakers, difficulties were experienced in describing the complex concepts in the ICF, e.g. defining and explaining the subtle differences between Support and Relationships (e3) and Attitudes (e4). The concepts of capacity and performance also caused many problems and in very few cases did participants cite a difference in the two, probably due to a lack of understanding. These difficulties might be reduced by the use of a well translated version of the ICF and since the study was undertaken, a rigorously translated Xhosa version of the ICF has been produced (Ka'Toni, personal communication).

Participants often reported no or few problems on the ICF; however further probing of the different domains after initial completion of the questionnaire revealed that they did have problems in these areas. The ICF often did not allow for identifying the exact problem and whether it was relevant or related to HIV. For example a number of people in the study cited problems of short term memory loss but it was not possible to establish whether it was HIV related or a problem associated with normal aging.

In summary the advantages of using the ICF included that areas of need were identified and that these were generally consistent with the literature. The data collection was standardised and findings can validly be compared to other studies, which use the ICF, both nationally and internationally. Environmental factors were found to have a major impact on the well-being of the participants. With the inclusion of this part of the ICF, these factors could be explored in a systematic manner

On the other hand there were problems relating to the understanding of concepts both linguistically and conceptually. There was a need to probe further as not all respondents reported problems on initial questioning using the ICF checklist. It was difficult to to determine whether the limitation was related to the presenting illness. A major constrain was the length of time required to administer the instrument and the fact that coding of information was very time consuming.

\section{Related to specific aims of the ICF}

The ICF did provide a scientific basis for understanding the functioning of people living with HIV in a resource poor environment. The conceptualisation of the different domains provided a considered structure within which to gather information.

Despite the researchers having had training in the use of the ICF, piloting of the instrument revealed several areas of confusion between the different researchers interpretation of domains. In addition, it was necessary to explain the concepts to the participants before they could respond appropriately and this explanation could have varied between researchers. The validity and reliability of the ICF as a common language might be threatened if adequate training is not provided and the approach to asking questions relating to the domains is not standardised. The issue of training is being addressed by users of the ICF and the Disability Italian Network has already offered structured training courses in the application of the instrument (Centre for Disease Control, 2004) and procedural manuals are being produced by ICF interested groups in the USA (Centre for Disease Control, 2003).

The ICF aims to provide a systematic coding scheme for health information systems. This is unlikely to be implemented if the full coding system and qualifiers are utilised. Data gathering 
took 30-45 minutes per participant and coding took even longer. The way forward might be to develop abbreviated lists which are applicable in certain circumstances, e.g. the codes useful in an acute hospital setting are different to those required in the community setting; stroke patients might have different limitations to those with a hearing impairment.

\section{CONCLUSION}

The ICF was found to be useful tool for providing a framework within which to explore the multifaceted functional problems associated with HIV.

The major difficulty encountered with the ICF was trying to explain sophisticated concepts such as performance and capacity to second (or third) language English speakers. There needs to be a rigorous translation using standardised methodology (Herdman, 1998) of the ICF into indigenous languages ${ }^{1}$, and further research to determine the reliability and validity of these versions. In the meantime, it is hoped that smaller studies such as this can provide useful information as to the strengths and weaknesses of the instrument. The collection of data related to health and health states is a vital complement to the information gained by the ICD and as such the refining and use of the ICF merits serious attention.

\section{Acknow ledgements}

The University of Cape Town Research Committee for funding; Dr C Orrell and the staff of the research site for support and assistance and the subjects for so patiently sharing their experiences with the researchers: Margie Schneider for help with the use of the ICF.

\section{REFERENCES}

Alubo, O 2002 Breaking the wall of silence: AIDS policy and politics in Nigeria. International Journal of Health Services, 32, 551-66.

Alubo, O, Zwandor, A, Jolayemi, T Omudu, E 2002 Acceptance and stigmatization of PLWA in Nigeria. AIDS Care, 14, 117-26.

Bilbao, A, Kennedy, C, Chatterji, S, Ustun, B, Barquero, J Barth, J 2003 The ICF: Applications of the WHO model of functioning, disability and health to brain injury rehabilitation. NeuroRehabilitation., 18, 239 - 250.

Bornman, J 2004 The World Health Organisation's terminology and classification: application to severe disability. Disabil Rehabil, 26, 182-8.

Centre for Disease Control 2004 ICF Clearing House Newsletter CDC 2004 http://www.cdc. gov/nchs/data/icd9/icfaprmayo4newslet.pdf

Centre for Disease Control 2003 ICF Clearing House Newsletter CDC 2004 http://www.cdc.gov/nchs/data/icd 9 licfaprmayo4newslet.pdf

Dorrington, R, Bradshaw, D, Johnson, L Budlender, D (2004). The demographic impact of HIV/AIDS in South Africa. National indicators for 2004. Cape Town: Centre for Actuarial Research, South African Medical Research Council and Actuarial Society of South Africa.

Heaton, RK, Marcotte, TD, Mindt, MR, Sadek, J, Moore, DJ, H, HB, McCutchan, JA, Reicks, C Grant, I 2004 The impact of HIV-associated neuropsychological impairment on everyday functioning. Journal of the International Neuropsychology Society10(3): 317-31, 10, 317-331.

Herdman, M 1998 A model of equivalence in the cultural adaptation of HRQoL instruments: the universalist approach. Quality of Life Research, 4, 323-335.
Hughes, J, Jelsma, J, McLean, E, Darder, M T Xolise 2004 Health related quality of life of persons living with HIV. Disability and Rehabilitation, 26, 371 - 376.

Medley, A, Garcia-Moreno, C, McGill, S Maman, S 2004 Rates, barriers and outcomes of HIV serostatus disclosure among women in developing countries, implications for prevention of mother-to-child transmission programmes. Bulletin of the World Health Organisation, 82, 299 - 307.

Murri, R, Fantoni, M, Del Borgo, C, Visona, R, Barracco, A, Zambelli, A, Testa, L, Orchi, N, Tozzi, V, Bosco, O Wu, AW 2003 Determinants of health-related quality of life in HIV-infected patients. AIDS Care, 15, 581-90.

Rosenbaum, P Stewart, D 2004 The World Health Organization International Classification of Functioning, Disability, and Health: a model to guide clinical thinking, practice and research in the field of cerebral palsy. Semin Pediatr Neurol, 11, 5-10.

Sibai, AM 2004 Mortality certification and cause-of death reporting in developing countries. Bulletin of the World Health Organisation, 82, 83.

World Health Organisation 2003 ICF Checklist WHO 2005 http://www3.who.int/ icf/checklist/icf-checklist.pdf

World Health Organisation 1980. International classification of impairments, disabilities and handicaps: A manual of classification relating to the consequences of disease. Geneva: WHO.

World Health Organization 2001. International Classification of Functioning, Disability and Health. Geneva: World Health Organization.

\footnotetext{
${ }^{1}$ Since the study was done, Ka'Toni, Eide, Jelsma, Loeb and Maart have produced a Xhosa translation of the ICF check-list. This is available from the first author on request.
} 